\title{
CURRENT PRACTICES RELATED TO FAMILY PRESENCE DURING ACUTE DETERIORATION IN ADULT EMERGENCY DEPARTMENT PATIENTS.
}

Family Presence During Acute Deterioration.

Megan J. Youngson, RN, BN, GDipNursPrac (Emergency Care), MNursPrac

School of Nursing and Midwifery, Deakin University, 221 Burwood Highway, Burwood, VIC 3125, Australia.

Critical Care Department, Ballarat Health Services, 1 Drummond St Nth, Ballarat, VIC 3350, Australia.

Email: megan.youngson@bhs.org.au

Professor Judy Currey, RN BN(Hons) GCertHE GCertSc(App Stats) PhD

Deakin University, Geelong, Australia; School of Nursing and Midwifery/ Centre for Quality and Patient Safety Research, Deakin University, 221 Burwood Highway, Burwood, VIC 3125, Australia.

Professor Julie Considine, RN, RM, BN, GDipNurs(Acute Care), GCertHE, MN, PhD Deakin University, Geelong, Australia; School of Nursing and Midwifery/ Centre for Quality and Patient Safety Research, 221 Burwood Highway, Burwood, VIC 3125, Australia/ Eastern Health - Deakin University Nursing and Midwifery Research Centre, Level 2, 5 Arnold Street, Box Hill, VIC 3128.

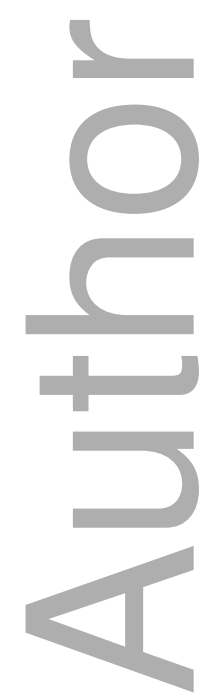

This is the author manuscript accepted for publication and has undergone full peer review but has not been through the copyediting, typesetting, pagination and proofreading process, which may lead to differences between this version and the Version of Record. Please cite this article as doi: $\underline{10.1111 / \text { jocn.13733 }}$

This article is protected by copyright. All rights reserved 
MS. MEGAN YOUNGSON (Orcid ID : 0000-0002-3304-0186)

PROF. JULIE CONSIDINE (Orcid ID : 0000-0003-3801-2456)

Received Date : 01-Aug-2016

Revised Date : 08-Dec-2016

Accepted Date : 03-Jan-2017

Article type :Original Article

\section{ABSTRACT}

Aims: To explore the characteristics and interactions of clinicians, patients and family members during management of the deteriorating adult patient in the Emergency Department.

Background: Previous research into family presence during resuscitation has identified many positive outcomes when families are included. However, over that last three decades the epidemiology of acute clinical deterioration has changed, with a decrease in in-hospital cardiac arrests and an increase in acute clinical deterioration. Despite the decrease in cardiac arrests research related to family presence continues to focus on care during resuscitation rather than care during acute deterioration.

Design: Descriptive exploratory using non-participatory observation.

Methods: Five clinical deterioration episodes were observed within a 50-bed, urban, Australian Emergency Department. Field notes were taken using a semi-structured tool to allow for thematic analysis.

Results: Presence, roles and engagement describe the interactions of clinicians, family members and patients whilst family are present during a patient's episode of deterioration. Presence was classified as no presence, physical presence and therapeutic presence.

Clinicians and family members moved through primary, secondary and tertiary roles during patients' deterioration episode. Engagement was observed to be superficial or deep.

There was a complex interplay between presence, roles and engagement with each influencing which form that the other could take.

Conclusions: Current practices of managing family during episodes of acute deterioration are complex and multifaceted. There is fluid interplay between presence, roles and engagement during a patient's episode of deterioration.

This article is protected by copyright. All rights reserved 
Relevance to Practice: This study will contribute to best-practice, provide a strong foundation for clinician education and presents opportunities for future research.

Keywords: Cardiopulmonary Resuscitation, Communication, Emergency Medicine, Emergency Nursing, Family, Patient Engagement

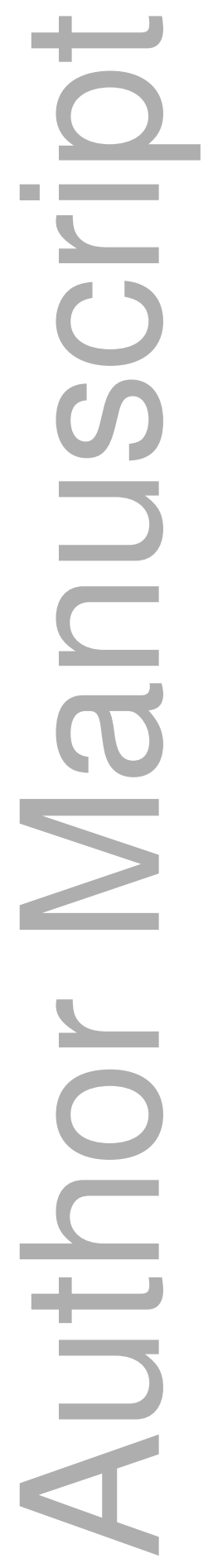

This article is protected by copyright. All rights reserved 


\section{SUMMARY BOX}

\section{What does this paper contribute to the wider global community?}

- This study is the first observational study of family presence during acute deterioration and provides important findings about the characteristics of family presence during management of the deteriorating adult Emergency Department patient.

- This study provides an understanding that including family during a patient's episode of deterioration is complex and multifaceted; with presence, roles and engagement describing the key characteristics of clinician-family-patient interactions.

- The understanding of family presence during acute deterioration provided by findings of this study significantly contributes to best-practice and highlights areas for future research.

\section{KEYWORDS}

Cardiopulmonary Resuscitation

Communication

Emergency Medicine

Emergency Nursing

Family

Patient Engagement

\section{INTRODUCTION}

Since its introduction in the early 1980s family presence during resuscitation has been a widely researched area of practice (Doyle et al. 1987, Robinson et al. 1998, Meyers et al. 2000, Holzhauser et al. 2006, Maxton 2008). Currently, family presence during 
resuscitation is defined as the presence of one or two family members in the room while a relative is undergoing resuscitation efforts (Doyle et al. 1987). Evidence suggests multiple benefits for the family, patient and clinicians when families are present during resuscitation (Doyle et al. 1987, Robinson et al. 1998, Meyers et al. 2000, Holzhauser et al. 2006, Maxton 2008). However, the epidemiology of acute clinical deterioration in developed countries has changed over the last three decades with a decrease in in-hospital cardiac arrests and an increase in management of acute clinical deterioration, most probably secondary to the introduction of rapid response teams (Buist et al. 2002, Bellomo et al. 2003, Campello et al. 2009, Konrad et al. 2010).

Further, in a number of healthcare settings family have been identified as an integral member of the patients healthcare journey with widespread acknowledgement of the importance of an effective family-patient-clinician relationship (Freemont et al. 2001, Arbuthnott et al. 2009, Meterko et al. 2010, Australian Commission on Safety and Quality in Health Care [ACSQHC] 2011, Boulding et al. 2011). An effective family-patient-clinician relationship has both clinical and business advantages, including decreased mortality rates, decreased readmission and length of stay and decreased costs per patient while also improving adherence to treatment regimens (Freemont et al. 2001, Arbuthnott et al. 2009, Meterko et al. 2010, ACSQHC 2011, Boulding et al. 2011). A quality family-patientclinician relationship has been identified as integral in providing safe and high quality healthcare for all patients (ACSQHC 2011). As a result family members are now being encouraged to participate in all aspects of the patients healthcare journey, including during deterioration (ACSQHC 2011).

However, despite the plethora of positive research pertaining to family presence during resuscitation (Doyle et al. 1987, Robinson et al. 1998, Meyers et al. 2000, Holzhauser et al. 2006, Maxton 2008), the changing epidemiology of deterioration (Buist et al. 2002, Bellomo et al. 2003, Campello et al. 2009, Konrad et al. 2010), and acknowledgement of the importance of family involvement in the patients' healthcare journey (Freemont et al. 2001, Arbuthnott et al. 2009, Meterko et al. 2010, ACSQHC 2011, Boulding et al. 2011) there is limited research regarding family presence during management of the deteriorating patient (Youngson et al. 2016).

\section{BACKGROUND}

\section{Effects of Family Presence During Resuscitation for Family}

This article is protected by copyright. All rights reserved 
Studies of the effect of family presence during resuscitation on family members have highlighted both benefits and concerns. Benefits for family members include improved grieving processes (Doyle et al. 1987, Robinson et al. 1998, Meyers et al. 2000, Holzhauser et al. 2006, Maxton 2008, Porter et al. 2015), reduced levels of anxiety (Meyers et al. 2000, Mangurten et al. 2006, Pasquale et al. 2010) and an increased understanding of the event (Meyers et al. 2000, Mangurten et al. 2006, Maxton 2008). Further, family members have overwhelmingly expressed their need and desire to be present during their relative's resuscitation (Doyle et al. 1987, Meyers et al. 2000, Grice et al. 2003, Mangurten et al. 2006, Duran et al. 2007). However, clinicians frequently cite concern for the emotional wellbeing of families who are present during resuscitation (Grice et al. 2003, Duran et al. 2007). Despite this concern, multiple studies show that while witnessing resuscitation families focus on the survival of the patient rather than the trauma of the event, and that witnessing the event was no more distressing than not witnessing the event (Doyle et al. 1987, Meyers et al. 2000, Holzhauser et al. 2006, Mangurten et al. 2006, Duran et al. 2007, Compton et al. 2011).

\section{Benefits of Family Presence During Resuscitation for Patients}

Again research findings identify both benefits and concerns for those patients whose family members are present during their resuscitation. Benefits include patients feeling an increased sense of comfort and support by having a family member within the resuscitation room (Eichhorn et al. 2001, Grice et al. 2003, Duran et al. 2007, McMahonParkes et al. 2009). Further, patients valued the advocacy role that family members were able to undertake, as families were able to provide a thorough and accurate health history, as well as, provide an explanation of the patients' health wishes (Eichhorn et al. 2001, McMahon-Parkes et al. 2009).

Clinicians cite concern that having family present during resuscitation may negatively impact on patient care, that family may become disruptive, that care of the family member may take away from the care of the patient and that treatment will be unnecessarily prolonged (Meyers et al. 2000, Grice et al. 2003, Duran et al. 2007, Günęs \& Zaybak 2009, Köberich et al. 2010). Despite these concerns, in the majority of cases family presence does not interrupt patient care (Doyle et al. 1987, Meyers et al. 2000, Mangurten et al. 2006) and there is no difference in time to radiology or completion of the resuscitation (Mangurten et al. 2006, Dudley et al. 2009). 


\section{Benefits of Family Presence During Resuscitation for Clinicians}

Clinicians have both concern and praise for including family during resuscitation. When families are present during resuscitation, clinicians have an increased awareness of their professional manner and therefore professional conduct during resuscitation has been shown to improve (Meyers et al. 2000, Mangurten et al. 2006). However, impaired team performance secondary to clinicians expressing increased feelings of stress and performance anxiety is frequently cited as a concern (Grice et al. 2003, Duran et al. 2007, Günęs \& Zaybak 2009, Köberich et al. 2010). Despite this concern clinician performance during resuscitations where families are present is unchanged (Meyers et al. 2000, Mangurten et al. 2006).

\section{Family Presence During Acute Deterioration}

Between $1.5 \%$ and $15 \%$ of Emergency Department (ED) patients experience clinical deterioration that fulfills ED-specific or hospital-wide Rapid Response Team (RRT) activation criteria at some stage during their ED care (Considine et al. 2012, Hosking et al. 2014, Considine et al. 2015, Mitchell Scott et al. 2015). Recent research has identified that emergency department clinicians have a predominantly positive attitude towards including family during a patient's episode of acute deterioration (Youngson et al. 2016). Clinicians perceived family presence during a patient's episode of deterioration to be a common dayto-day practice with $77.6 \%$ of clinicians stating that family presence during acute deterioration was mostly or always a part of their day-to-day practice (Youngson et al. 2016). Additionally $80.2 \%$ of clinicians felt comfortable supporting family who are present during the episode of deterioration (Youngson et al. 2016). Further, gender, profession, country of birth, education level and years of experience all impacted on clinicians' attitudes, beliefs and perceptions of including family during a patient's episode of deterioration (Youngson et al. 2016).

Despite these positive results, this study was based on clinician beliefs of current practice and did not include whether these beliefs are being transferred into actual practice (Youngson et al. 2016). Therefore, a study is required to identify whether family presence during a patient's episode of acute deterioration is actually occurring in current practice.

\section{Summary}

In summary, it has been established that family presence during resuscitation has benefits for families, patients and clinicians. Given the changing epidemiology of deterioration, the 
acknowledgement of the importance of family involvement throughout the entire patient journey and the above findings related to family presence during resuscitation, a better understanding of family presence during management of the deteriorating patient is warranted. Despite positive clinician attitudes towards including family during a patient's episode of acute deterioration and a belief that family presence during acute deterioration is common practice, there is no published literature identifying what is actually occurring in current practice. The aim of this study therefore is to explore the characteristics and interactions of clinicians, patients and family members during management of the deteriorating adult patient in the Emergency Department.

\section{METHODS:}

Non-participatory observations of acute, clinical deterioration episodes of adult ED patients was conducted over a period of 10 weeks. The study involved three participant groups. Group 1 included five patients who experienced an episode of deterioration during their stay in $E D$ and who recovered such that they were able to give informed consent prior to leaving the ED. Group 2 included twelve ED clinicians who were caring for the patients in Group 1. Group 3 included nine relatives or significant others of Group 1 patients and who were in the ED during the patient's episode of deterioration.

The study was conducted in a 50-bed ED of a major urban hospital in Victoria, Australia. The ED cares for approximately 1500 patients per week (Northern Heath 2016). On average there are 76 RRT activations per month, with hypotension and tachycardia the most common causes for activation (Considine et al. 2012). The ED at the study site used an ED specific RRT known as Clinical Instability Criteria (Table 1) (Considine et al. 2012)

Patient participants were identified for the study through activation of the ED RRT, activation of an emergency buzzer, or request for an urgent emergency physician review. Observation commenced at notification of the deterioration and ceased when the patient returned to normal physiological parameters or when there was no clinical need for the RRT to continue to manage the patient. In order to qualify for the study the patient participant required relatives or significant others within the ED at the time of their deterioration. Further, as participants in the study were required to give informed consent participants whose English language skills were not at a level where they could provide informed consent, participants under the age of 18 years and those with mental or cognitive impairment were excluded from the study. 
Data were collected through taking field notes during non-participatory observation over 10 weeks. A semi-structured observation tool, based on Rollans et al.'s (2013) fieldwork development framework, was used to guide data collection. Two nurse academics, who were experts in emergency and critical care and tool development, reviewed the tool to ensure appropriate and comprehensive content. The tool allowed for collection of data regarding patient, family member and clinician characteristics and to enable an understanding of the interactions between patients, families, nurses and doctors. The tool allowed for documentation that described clinician-family-patient interactions, participant behaviours, communication, rapport, decision-making patterns, non-verbal communication, participant reactions and mood/atmosphere of the room. The tool also allowed for documentation of clinical and contextual data such as the nature of the deterioration, clinical management and involvement of other staff.

When a patient met the study inclusion criteria, one researcher undertook the nonparticipatory observation of the clinical deterioration episode. The same researcher undertook all of the observations in order to provide consistency with observation and field note taking. The researcher took the field notes while management of the deteriorating patient occurred, allowing for direct capture of data as the deterioration was managed. The researcher stood in the corner of the cubicle and did not interact or take part in the management of the deterioration. If the patient was moved to another area within the ED the researcher followed the participants but again did not interact. In order to decrease the risk of bias the researcher reflected and reviewed the field notes after each deterioration episode.

Ethics approval from the Human Research and Ethics Committee at Deakin University and the study site was granted. Guardianship consent for all ED clinicians was obtained by the ED Program Director. During data collection periods individual clinicians were given the opportunity to opt out of the study. Informed consent from family and patients was obtained post observation of the clinical deterioration episode. Informed consent was obtained at this time as knowledge of the observer and study may have caused changes in behaviour and would therefore not have reflected a true picture of current practices. Additionally, clinical deterioration can be difficult to predict and when it occurs requires immediate attention from clinicians. Delaying intervention in order to get consent would not have been ethically appropriate. The patient and family members were approached and 
had the study explained to them once the patient's episode of deterioration had been managed and the patient was deemed stable by the treating team. If any of the potential participants did not want to participate in the study the field notes from the observations were not used and destroyed confidentially. Of the episodes of deterioration observed, only one family member and one patient (from two separate deterioration episodes) declined to participate in this study, therefore the observation notes from each of these deterioration episodes were destroyed confidentially and the data was not used in this or any other study.

Data were analysed using coding and thematic analysis according to Braun \& Clarke's (2006) six-phase framework. This validated framework involves familiarising yourself with the data, initiating codes, identifying themes, reviewing, defining and naming themes and finally producing the thematic report (Braun et al. 2006). Trustworthiness of this study was ensured as the design, methods, analysis and findings were reviewed by two senior academic nurses, the methodology has been clearly explained so that the study may be repeated and examples of the observations are given (Schneider et al. 2014).

\section{RESULTS:}

Data saturation occurred after five observed deterioration episodes, involving five patients, nine family members and twelve ED clinicians. Each episode of deterioration lasted between 30 to 50 minutes. Between one and four family members were in attendance during each deterioration episode. One group of family members were removed from the cubicle when the patient began to deteriorate, although in this event, one relative returned part way through the deterioration to assist in managing the patient. Characteristics of the participants are presented in Table 2.

Thematic analysis of the field notes revealed three key themes: presence, roles and engagement. Each of these themes will be discussed in the sections to follow.

\section{Presence}

The theme of 'presence' pertained to where family members were situated while the deteriorating patient was being managed. Presence itself took three forms: no presence, physical presence and therapeutic presence.

\section{No Presence}


No presence' occurred when family members were not present while the deteriorating patient was managed. As the patient's condition began to deteriorate families were inadvertently or purposefully removed by clinicians from the cubicle. Clinicians appeared solely focused on managing the patient. Family members were not recognised nor identified as being present, such that when clinicians moved into the cubicle to manage the deterioration, family were inadvertently displaced out of the cubicle resulting in physical separation of the family and patient. Physical separation appeared to have several negative effects on the family. Family members appeared to have an increase in anxiety and worry, as evidenced by tears and distress.

\section{Physical Presence}

'Physical presence' occurred when family members were physically present while their relative was being managed, but there was no therapeutic interactions between the family members and clinicians. For example, family members were observed standing in the corner of the cubicle or upright against the wall. There was only superficial or perfunctory acknowledgement by clinicians of the family members.

Physical presence appeared to have both positive and negative effects on the family members. Family members appeared to be anxious and overwhelmed by what they were witnessing as evidenced by the shocked look on their faces and expression of tense body language. However, family members were not teary or distressed. During physical presence clinicians were observed to withhold information and did not consult or explain their actions to the family members. It appeared that family members were unable to seek clarification and an explanation of events. Family members were observed to attempt to seek clarification and then stopped mid-question when it appeared the clinicians were not listening to them. Family members were not observed to seek clarification again.

\section{Therapeutic Presence}

'Therapeutic presence' occurred when family members were physically with patients during the episode of deterioration and experienced therapeutic interactions between themselves, clinicians and the patient. Two-way communication and frequent interactions between the family member, patient and clinicians took place.

There appeared to be positive benefits for the family members, patients and clinicians during therapeutic presence. Family members would laugh, move freely within the room 
and physically comfort the patient. The body language of family members appeared to become more relaxed as evidenced by a cessation of the look of worry that had been expressed on their faces. During therapeutic presence the patient also appeared to relax as evidenced by the beginning of casual conversation and joking with their family. As the family members and patient began to relax the clinicians too appeared to relax as evidenced by an increase in interactions between themselves, the family members and patient. Clinicians ensured clarification and understanding of the event with the family members and patient.

\section{Roles}

The key theme 'roles' pertained to the 'activity' adopted by the doctor, nurse or family members during management of the deteriorating patient. The roles were divided into primary, secondary and tertiary roles.

\section{Primary Role}

The primary role pertained only to clinicians and occurred at the very beginning of managing the deteriorating patient. Clinicians focused solely on understanding the deterioration and carrying out assessment and management strategies in order to stabilise the deteriorating patient. The priority of stabilising the patient excluded clinicians taking on any other potential roles.

\section{Secondary Role}

As understanding and management of the deteriorating patient occurred the doctor, nurse and family members moved into secondary roles. Most often the doctor appeared to take on the role of overseer, delegator, decision maker and engager. Most often the nurse appeared to take on the role of implementing therapeutic interventions in order to stabilise/manage the deteriorating patient. Family members took on roles of interpreter, information distributor and/or comforter.

The doctor's secondary role allowed them to oversee management of the deterioration without being physically involved. The doctor delegated therapeutic interventions and made decisions surrounding treatment and management of the deteriorating patient. By stepping back from physically undertaking the therapeutic interventions used to stabilise the clinical condition of the patient, the doctor was able to take on the role of engager. The role of engager appeared to involve interacting therapeutically with the patient and family. This was evidenced by two-way communication between the doctor, family and patient 
surrounding events leading up to the deterioration, why the deterioration occurred, what interventions were occurring to stabilise the patient and what the plan was for the immediate future. It was observed that the engager would clarify family member and patient understanding of the deterioration event and ensure any family member or patient questions were answered adequately.

For the majority of the time the nurse's secondary role did not appear to vary from their primary role. The nurse continued to manage and stabilise the deteriorating patient. However, unconscious secondary role delegation appeared to occur whereby in some cases the doctor and nurse freely interchanged their secondary roles. If the doctor appeared flustered, didn't acknowledge the family member or appeared to become unsure about the event, they appeared to become 'stuck' in their primary role of being solely focused on the management of the deteriorating patient. It appeared that if the nurse became aware and acknowledged these behaviours displayed by the doctor, the nurse took on the role of engager. When nurses undertook the role of engager, they displayed the same characteristics as that described previously for the doctors in the engager role. There appeared to be a mutual understanding among clinicians that the role of managing the deteriorating patient and the role of engager held equal importance.

During this time some family members appeared to be able to take on their secondary role of being interpreter, information distributor and/or comforter. Family were seen to interpret information between the patient and clinician, they divulged health information on behalf of the patient to clinicians and they distributed information about the deterioration to other family members who were not present during the deterioration episode. Family members were also seen to provide comfort and support to the patient through physical touching, hugging and handholding, as well as through communicating words of encouragement such as 'you're doing well' or 'I'm just here'.

\section{Tertiary Role}

The tertiary role appeared to only occur after therapeutic interventions had occurred and the patient's condition stabilised. Providing the nurse had not previously undertaken the role of engager it was at this point that the nurse took on the role of engager. The tertiary role of engager involved developing a therapeutic relationship between the nurse, family member and patient. The tertiary role of engager appeared to have the same 
characteristics as the secondary role of engager - therapeutic interactions with the patient and family, two-way communication and clarification of understanding of the event.

\section{Engagement}

The key theme 'engagement' described the depth of interaction and connection experienced between the clinicians, patient and family members. There were two forms of engagement: superficial engagement and deep engagement.

\section{Superficial Engagement}

'Superficial engagement' appeared to occur when the interactions and emotional connection between clinicians and family members were at a superficial level. In this state interactions between the clinicians, family members and patient were formal, habitual and perfunctory. Family members were often unacknowledged and left in a vulnerable position. For example, one family member was left to stand in the corner of the resuscitation room holding the patients vomit stained clothing. During superficial engagement family members were observed to stay silent and not ask questions or seek clarification of the events taking place around them. The family and patient appeared to experience inadvertent withholding of information by clinicians. For example, in one event the patient's cardiac rhythm had stabilised by returning to a normal sinus rhythm as a consequence of appropriate treatment. However, clinicians did not tell the family member that this had occurred. Further, family members frequently appeared overwhelmed and confused by the situation. This was evidenced by a look of shock and confusion on their faces, they became teary, had an inability to move freely within the room and were constantly apologising for being in the way. It appeared that as the family member became more anxious and worried the patient too became more anxious and worried. This was evidenced by an increasing look of worry on the patients face, decreased communication with family and clinicians, and a display of tense body language.

\section{Deep Engagement}

'Deep engagement' appeared to occur when the interactions and emotional connection between the clinicians and family member were at a deep and therapeutic level. These interactions were observed to be warm, empathetic and personal. Deep engagement appeared to have positive effects on the family, patient and clinicians. Family members and the patient sought clarification and asked questions surrounding the event and interventions. During this time there appeared to be inadvertent or purposeful education 
provided by the clinicians to the family and patient. For example, a clinician explained to the family member that with administration of the medicine the family member should be able to see a decrease in the heart rate on the monitoring screen. An understanding of the event and the therapeutic interactions appeared to dissipate feelings of anxiety and worry from the patient and family. This was evidenced by an increase in informal chatter, laughing and joking among the family members and patient. Further, clinicians were observed to join in with the informal chatter, provide physical comfort to the patient and display purposeful behaviours while undertaking interventions.

\section{Complex Interplay Between Presence, Roles and Engagement}

There was a complex interplay between presence, roles and engagement, with each influencing the form that the other took. The type of presence and the undertaking of roles influenced the type of engagement that occurred.

It appeared that there was interplay between no presence, physical presence, primary roles and superficial engagement. While undertaking primary roles, due to the prioritisation of patient safety and stabilisation of the deteriorating patient, it appeared that no presence or physical presence occurred with superficial engagement. During no presence and physical presence it was observed that family members were unable to undertake their secondary role of supporter and comforter for the patient, and therefore it appeared that deep engagement and therapeutic presence was an impossibility.

It appeared that once stabilistation of the patient had begun, the type of presence changed. It appeared that clinicians who were able to freely acknowledge and engage in two-way communication with family members and the patient appeared to move into therapeutic presence, while those clinicians who remained solely focused on actioning therapeutic interventions and stabilisation of the patient practiced physical presence.

It appeared that the family members' secondary role of being interpreter, information distributor and/or comforter relied on a clinician transitioning into therapeutic presence and deep engagement. In order to move into therapeutic presence and deep engagement clinicians had to have undertaken the role of engager. There appeared to be an interplay between the secondary role of engager, therapeutic presence and deep engagement.

Finally, it was apparent that as clinicians undertook the tertiary role they were able to move into therapeutic presence and enter deep engagement with both the family member and 
the patient. One clinician could not undertake the roles of manager of the deteriorating patient and engager at the same time. Therefore, it appeared that for some clinicians' therapeutic presence and deep engagement could not occur until towards the end of the deterioration episode.

Figure 1 highlights the complex interplay of presence, roles and engagement that occurs throughout the patient's episode of deterioration.

\section{DISCUSSION}

This study identified three types of presence that occurred during a patient's episode of deterioration. No presence and physical presence resulted in predominantly negative clinician-family-patient interactions, while therapeutic presence resulted in positive clinician-family-patient interactions. Previous research related to family presence during resuscitation has highlighted the importance of presence (Mangurten et al. 2006, Maxton 2008, McMahon-Parkes et al. 2009) but has not identified the type or quality of presence that occurs. A previous meta-analysis of nursing research identified that clinician characteristics impact on the quality of presence experienced by the patient and family (Finfgeld-Connett 2006). Clinicians with personal and professional maturity were able to provide a higher quality presence than clinicians who were personally or professionally immature (Finfgeld-Connett 2006). In this study, it was noted that several clinicians progressed to therapeutic presence earlier than other clinicians. The study precluded analysis of the role experience, knowledge and maturity however, further research identifying the characteristics of those clinicians who competently progressed to therapeutic presence is warranted.

This study showed that clinicians and family members moved through primary, secondary and tertiary roles during a patient's episode of deterioration. Although these roles have never been identified together in one study related to family presence during resuscitation or deterioration, a number of these roles have been identified in separate studies related to resuscitation and deterioration (Eichhorn et al. 2001, Thomas et al. 2007, Maxton 2008, Santiano et al. 2011, Prince et al. 2014). During management of the deteriorating patient doctors took on the primary role of rescuer, followed by the secondary role of overseer and engager. Although a number of previous studies identify that doctors take on the role of rescuer and overseer there is no identification of the role of engager in medical staff 
(Thomas et al. 2007, Prince et al. 2014). To date this study is the first to acknowledge the role of engager that doctors undertake during management of a deteriorating patient.

During episodes of patient deterioration nurses predominantly took on the primary role of rescuer, the secondary role of manager of patient stabilisation and the tertiary role of engager. These findings support those of previous studies that showed nurses' roles during management of a deteriorating patient involved ongoing assessment, prioritising interventions, re-evaluating risk and participating in the management plan (Santiano et al. 2011). Despite no identification of the engager roles in Santiano et al.'s (2011) study a number of published studies related to resuscitation did identify the role of a support person (Eichhorn et al. 2001, James et al. 2010, James et al. 2011). It must be noted that the support role identified in published research is the nurses' only role (Eichhorn et al. 2001, James et al. 2010, James et al. 2011). This is in contrast to the current study where the nurse not only took on the role of engager but also managed the patient during their deterioration episode.

Engagement occurred in two forms: superficial and deep. Level of engagement has not previously been studied in research related to family presence during resuscitation and deterioration. However, the importance of quality engagement with families and patients has been nationally acknowledged within Australia (ACSQHC 2011, Health Consumers Queensland 2012). Quality engagement must have the following characteristics: consumer participation in decision-making, person-centred values, mutual respect and provide adequate support for consumers (Health Consumers Queensland 2012). Quality engagement allows for clinicians to inform, consult, involve, collaborate and empower consumers (Health Consumers Queensland 2012). Deep engagement provided an environment whereby there was open, respectful, two-way communication between clinicians, family members and patients, family members and patients appeared to be supported by clinicians through education and physical comfort. These characteristics seen in deep engagement are deemed to be essential when providing quality engagement therefore adding to the strength of the study findings.

\section{Limitations}

There are a number of limitations that should be considered when interpreting the study findings. First, this study occurred at a single site that may have differing characteristics to other sites. Further, this ED may have differing characteristics to other acute areas within 
the hospital. Therefore, the transferability of the study results to other EDs or other areas of care may be limited. Second, the exclusion criteria may have prevented a number of vulnerable patients and families from being included within this study and so may have influenced the study results. The transferability of the current study to vulnerable patient and family populations is not claimed. Third, there was only observation of 5 deterioration episodes. Although these observations comprise an adequate sample size in qualitative research, providing there is saturation of themes and richness of data (Schneider et al. 2013), the small sample size must be considered when interpreting results. However, it must be noted that each observed episode lasted between 30 to 50 minutes. Therefore, although only a small number of episodes were observed, there was in fact a significant amount of time through which to observe the interactions of clinicians, patients and family members during management of the deterioration. Further, despite the small sample size this study provides robust data on which to base a more comprehensive study that further analyses current practices of family presence during patient deterioration and builds on the themes; presence, roles and engagement, found during this study.

\section{CONCLUSIONS:}

One or more family members are often present during episodes of acute deterioration during emergency care of patients. The interactions between clinicians, family members and patients whilst family are present during a patient's episode of deterioration is complex and influenced by presence, roles and engagement. This study has identified that the type of presence and engagement can very much impact on the quality of care received by family members and patients who experience a deterioration episode with an emergency department. Further, this study highlights another area of healthcare where family members can actively participate in patients' care and management. As patients deteriorate in many areas within acute healthcare, further investigation of how families are cared for when a patient deteriorates in other areas such as general wards and critical care units is required.

\section{RELEVANCE TO PRACTICE:}

The findings of this study provide an initial understanding of a common but previously poorly understood practice. This study makes a strong contribution to best-practice. Future research should involve larger populations in order to strengthen the findings of this study and explore the influence, if any, of clinician experience and education on family presence. Future findings combined with this studies findings could then be used to inform policy and 
education related to the best-practice management of families during a patient's episode of deterioration. Based on this studies findings it is anticipated that best-practice will suggest that policies should include processes that aid in enhancing the positive attributes of presence, roles and engagement and support family to remain with the patient during an episode of deterioration. Education should provide clinicians with an understanding of the types of presence and engagement that can occur while including family during a patient's episode of deterioration and the varying roles that clinicians can take during this time.

\section{REFERENCES}

Arbuthnott A \& Sharpe D (2009) The effect of physician-patient collaboration on patient adherence in non-psychiatric medicine. Patient Education and Counseling 77, 60-67.

Australian Commission on Safety and Quality in Healthcare (2011) National Safety and Quality Health Service Standards. ACSQHC, Sydney, Australia.

Bellomo R, Goldsmith D, Uchino S, Buckmaster J, Hart GK, Opdam H, Silvester W, Doolan L \& Gutteridge $G$ (2003) A prospective before-and-after trial of a medical emergency team. Medical Journal of Australia 179, 283-287. 
Boulding W, Glickman SW, Manary MP, Schulman KA \& Staelin R (2011) Relationship between patient satisfaction with inpatient care and hospital readmission within 30 days. The American Journal of Managed Care 17, 41-48.

Braun V \& Clarke V (2006) Using thematic analysis in psychology. Qualitative Research in Psychology 3, 77-101.

Buist MD, Moore GE, Bernard SA, Waxman BP, Anderson JN \& Nguyen TV (2002) Effects of a medical emergency team on reduction of incidence and mortality from unexpected cardiac arrests in hospital: preliminary study. British Medical Journal 324, 387-390.

Campello G, Granja C, Carvalho F, Dias C, Azvedo LF \& Costa-Pereira A (2009) Immediate and long-term impact of medical emergency teams on cardiac arrest prevalence and mortality: a plea for periodic basic life-support training programs. Critical Care Medicine 37, 3054-3061.

Compton S, Levy P, Griffin M, Waselewsky D, Mango LM \& Zalenski R (2011) Familywitnessed resuscitation: bereavement outcomes in an urban environment. Journal of Palliative Medicine 14, 715-721.

Considine J, Lucas E \& Wunderlich B (2012) The uptake of an early warning system in an Australian emergency department: a pilot study. Critical Care and Resusciation 14, 135141.

Considine J, Rawet J \& Currey J (2015) The effect of a staged, emergency department specific, rapid response system on reporting of clinical deterioration. Australasian Emergency Nursing Journal 18, 218-216.

Doyle CJ, Post H, Burney RE, Maino J, Keefe M \& Rhee KJ (1987) Family participation during resuscitation: an option. Annals of Emergency Medicine 16, 673-675.

Dudley NC, Hansen KW, Furnival RA, Donaldson AE, Van Wagenen KL \& Scaife ER (2009) The effect of family presence on the efficiency of pediatric trauma resuscitations. Annals of Emergency Medicine 53, 777-784. 
Duran CR, Oman KS, Abel JJ, Koziel VM \& Szymanski D (2007) Attitudes toward and beliefs about family presence: a survey of healthcare providers, patients' families and patients. American Journal of Critical Care 16, 270-279.

Eichhorn DJ, Meyers TA, Guzzetta CE, Clark AP, Klein JD, Taliaferro E \& Calvin AO (2001) Family presence during invasive procedures and resuscitation: hearing the voice of the patient. The American Journal of Nursing 101, 48-55.

Finfgeld-Connett D (2006) Meta-synthesis of presence in nursing. Journal of Advanced Nursing 55, 708-714.

Freemont AM, Cleary PD, Hargraves JL, Rowe RM, Jacobson NB \& Ayanian JZ (2001) Patient-centred processes of care and long-term outcomes of myocardial infarction. Journal of General Internal Medicine 16, 800-808.

Grice AS, Picton P \& Deakin CDS (2003) Study examining attitudes of staff, patients and relatives to witnessed resuscitation in adult intensive care units. British Journal of Anaesthesia 91, 820-824.

Günęs ÜY \& Zaybak A (2009) A study of Turkish critical care nurses' perspectives regarding family-witnessed resuscitation. Journal of Clinical Nursing 18, 2907-2915.

Health Consumers Queensland (2012) Consumer and Community Engagement Framework. Queensland Government, Queensland, Australia.

Holzhauser K, Finucane J \& De Vries SM (2006) Family presence during resuscitation: a randomized controlled trial of the impact of family presence. Australasian Emergency Nursing Journal 8, 139-147.

Hosking J, Considine J \& Sands N (2014) Recognising clinical deterioration in emergency department patients. Australasian Emergency Nursing Journal 17, 59-67.

James J, Cottle E \& Hodge D (2010) A phenomenological exploration of health care Chaplains (HCC's) and registered nurses (RN's) support of family members during resuscitation of their loved one. Scottish Journal of Healthcare Chaplaincy 13, 9-13. 
James J, Cottle E \& Hodge D (2011) Registered nurses and health care Chaplains experiences of providing the family support person role during family witnessed resuscitation. Intensive and Critical Care Nursing 27, 19-26.

Köberich S, Kaltwasser A, Rothaug O \& Albarran J (2010) Family witnessed resuscitation - experience and attitudes of German intensive care nurses. Nursing in Critical Care 15, 241-250.

Konrad D, Jäderling G, Bell M, Granath F, Ekbom A \& Martling CR (2010) Reducing inhospital cardiac arrest and hospital mortality by introducing a medical emergency team. Intensive Care Medicine 36, 100-106.

Mangurten J, Scott SH, Guzzetta CE, Clark AP, Vinson L, Sperry J, Hicks B \& Voelmeck W (2006) Effects of family presence during resuscitation and invasive procedures in a pediatric emergency department. Journal of Emergency Medicine 32, 225-233.

Maxton FJC (2008) Parental presence during resuscitation in the PICU: the parents' experience. Journal of Clinical Nursing 17, 3168-3176.

McMahon-Parkes K, Moule P, Benger J \& albarran JW (2009) The views and preferences of resuscitated and non-resuscitated patients towards family-witnessed resuscitation. International Journal of Nursing Studies 46, 220-229.

Meterko M, Wright S, Lin H, Lowy W \& Cleary PD (2010) Mortality among patients with acute myocardial infarction: the influences of patient-centered care and evidence-based medicine. Health Services Research 45, 1188-1204.

Meyers TA, Eichhorn DJ, Guzzetta CE, Clark AP, Klein JD, Taliaferro E \& Calvin A (2000) Family presence during invasive procedures and resuscitation: the experience of family members, nurses and physicians. American Journal of Nursing 100, 32-42.

Mitchell Scott B, Considine J \& Botti M (2015) Unreported clinical deterioration in emergency department patients: a point prevalence study. Australasian Emergency Nursing Journal 18, 33-41. 
Northern Health (2016) Services. Northern Health, Victoria, Australia at: http://www.nh.org.au/services (accessed 22 April 2016).

Pasquale MA, Pasquale MD, Baga L, Eid S \& Leake J (2010) Family presence during trauma resuscitation: ready for primetime? The Journal of Trauma, Injury, Infection and Critical Care 69, 1092-1100.

Porter JE, Cooper SJ \& Taylor B (2015) Family presence during resuscitation (FDPR): a survey of emergency personnel in Victoria, Australia. Australasian Emergency Nursing Journal 18, 98-105.

Prince CR, Hines EJ, Chyou PH \& Heegeman DJ (2014) Finding the key to a better code: code team restructure to improve performance and outcomes. Clinical Medicine and Research 12, 47-57.

Robinson SM, Mackenzie-Ross S, Campbell Hewson GL, Egleston CV \& Prevost AT (1998) Psychological effect of witnessed resuscitation on bereaved relatives. The Lancet 352, 614-617.

Rollans M, Meade T, Schmeid V \& Kemp L (2013) Capturing clinician-client interaction: development of the 4D\&4R observation tool. Nurse Researcher 20, 11-19.

Santiano N, Young L, Baramy LS, Cabrera R, May E, Wegner R, Butt D \& Parr M (2011) The impact of the medical emergency team on the resuscitation practice of critical care nurses. British Medical Journal Quality and Safety 20, 115-120.

Schneider Z, Whitehead D, LoBiondo-Wood G \& Haber J (2013) Nursing and Midwifery Research: methods and appraisal for evidence-based practice $4^{\text {th }}$ edn. Elsevier, New South Wales, Australia.

Schneider Z, Whitehead D, LoBiondo-Wood G \& Haber J (2014) Nursing and Midwifery Research: methods and appraisal for evidence-based practice $5^{\text {th }}$ edn. Elsevier, New South Wales, Australia. 
Thomas K, VanOyen-Force M, Rasmussen D, Dodd D \& Whildin S (2007) Rapid response team: challenges, solutions, benefits. Critical Care Nurse 27, 20-27.

Youngson MJ, Currey J \& Considine J (2016) Family presence during management of acute deterioration: clinician attitudes, beliefs and perceptions of current practice. Australasian Emergency Nursing Journal 19, 159-165.

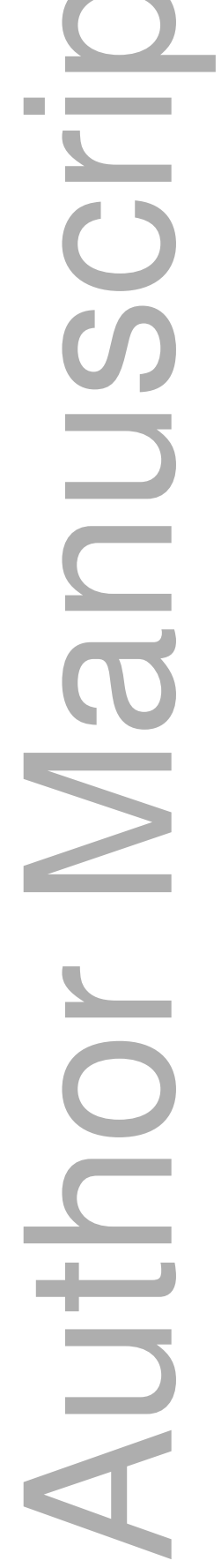


Table 1 Clinical Instability Criteria (Considine et al. 2012, p. 136)

\begin{tabular}{ll}
\hline Parameter & Criteria \\
\hline Airway & Stidor, upper airway obstruction, threatened airway \\
Respiratory Rate & $<10$ OR $>30$ breaths/minute \\
& $<90 \%$ with O2 flow rate 10 litres/minute via Hudson \\
SpO2 & Mask \\
Arterial Blood Gas & $\mathrm{pH}<7.20$ \\
Systolic Blood Pressure & $<90 \mathrm{mmHg}$ OR $>200 \mathrm{mmHg}$ \\
Heart Rate & $<50 \mathrm{OR}>120$ beats/minute \\
Urine Output & $<20 \mathrm{mls} /$ hour OR $<100 \mathrm{mls} / 6$ hours \\
Conscious State & Sudden decrease in the level of consciousness (fall in \\
Seizure & GCS $>2)$ \\
Nurse worried about patient & Repeated or prolonged \\
\hline
\end{tabular}

SpO2 peripheral capillary oxygen saturation; O2 oxygen; GCS Glasgow Coma Scale.

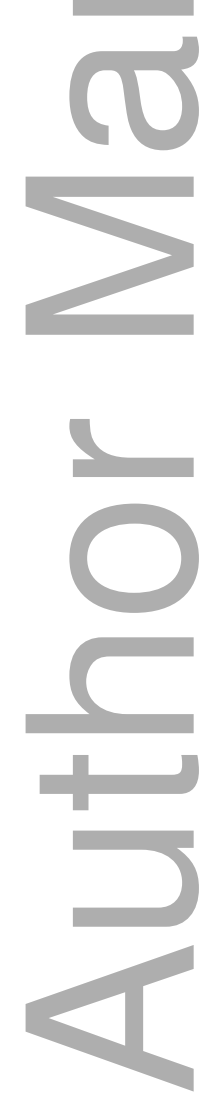


Table 2 Characteristics of Participants Observed During Deterioration Episodes

\begin{tabular}{|c|c|c|c|c|}
\hline \multirow[t]{2}{*}{ Characteristic } & \multicolumn{4}{|c|}{ Group } \\
\hline & $\begin{array}{c}\text { Patient } \\
\mathrm{n}(\%)\end{array}$ & $\begin{array}{c}\text { Family } \\
\mathrm{n}(\%)\end{array}$ & $\begin{array}{l}\text { Nurse } \\
\text { n (\%) }\end{array}$ & $\begin{array}{c}\text { Doctor } \\
\text { n (\%) }\end{array}$ \\
\hline Age & $\begin{array}{c}58(34- \\
80.5)^{\star}\end{array}$ & $n / a$ & $n / a$ & $n / a$ \\
\hline Gender & & & & \\
\hline Female & $3(60)$ & $5(55.6)$ & $6(85.7)$ & $2(40)$ \\
\hline Male & $2(40)$ & $4(44.4)$ & $1(14.3)$ & $3(60)$ \\
\hline Relationship to Patient & $\mathrm{n} / \mathrm{a}$ & & $\mathrm{n} / \mathrm{a}$ & $\mathrm{n} / \mathrm{a}$ \\
\hline Daughter & & $1(11.1)$ & & \\
\hline Father & & $1(11.1)$ & & \\
\hline Mother & & $1(11.1)$ & & \\
\hline Partner & & $1(11.1)$ & & \\
\hline Sister & & $2(22.2)$ & & \\
\hline Son & & $2(22.2)$ & & \\
\hline Wife & & $1(11.1)$ & & \\
\hline Years of Experience & $\mathrm{n} / \mathrm{a}$ & $n / a$ & $8(4-15)^{*}$ & $6(3.5-9.3)^{*}$ \\
\hline Level of Appointment & $n / a$ & $n / a$ & & \\
\hline RN with nil PG Quals. & & & $2(28.6)$ & \\
\hline RN with PG Quals. & & & $3(42.9)$ & \\
\hline CNS & & & $2(28.6)$ & \\
\hline Registrar & & & & $3(60)$ \\
\hline Emergency Physician & & & & $2(40)$ \\
\hline Country of Birt| & & & & \\
\hline Australia & $2(40)$ & $3(33.3)$ & $7(100)$ & $1(20)$ \\
\hline Italy & $2(40)$ & $1(11.1)$ & 0 & 0 \\
\hline Malaysia & 0 & 0 & 0 & $3(60)$ \\
\hline Malta & 0 & $1(11.1)$ & 0 & 0 \\
\hline Sri Lanka & 0 & 0 & 0 & $1(20)$ \\
\hline Turkey & $1(20)$ & $4(44.4)$ & 0 & 0 \\
\hline
\end{tabular}

RN Registered Nurse; PG postgraduate; Quals. Qualifications; CNS Clinical Nurse Specialist.

* median (IQR) 


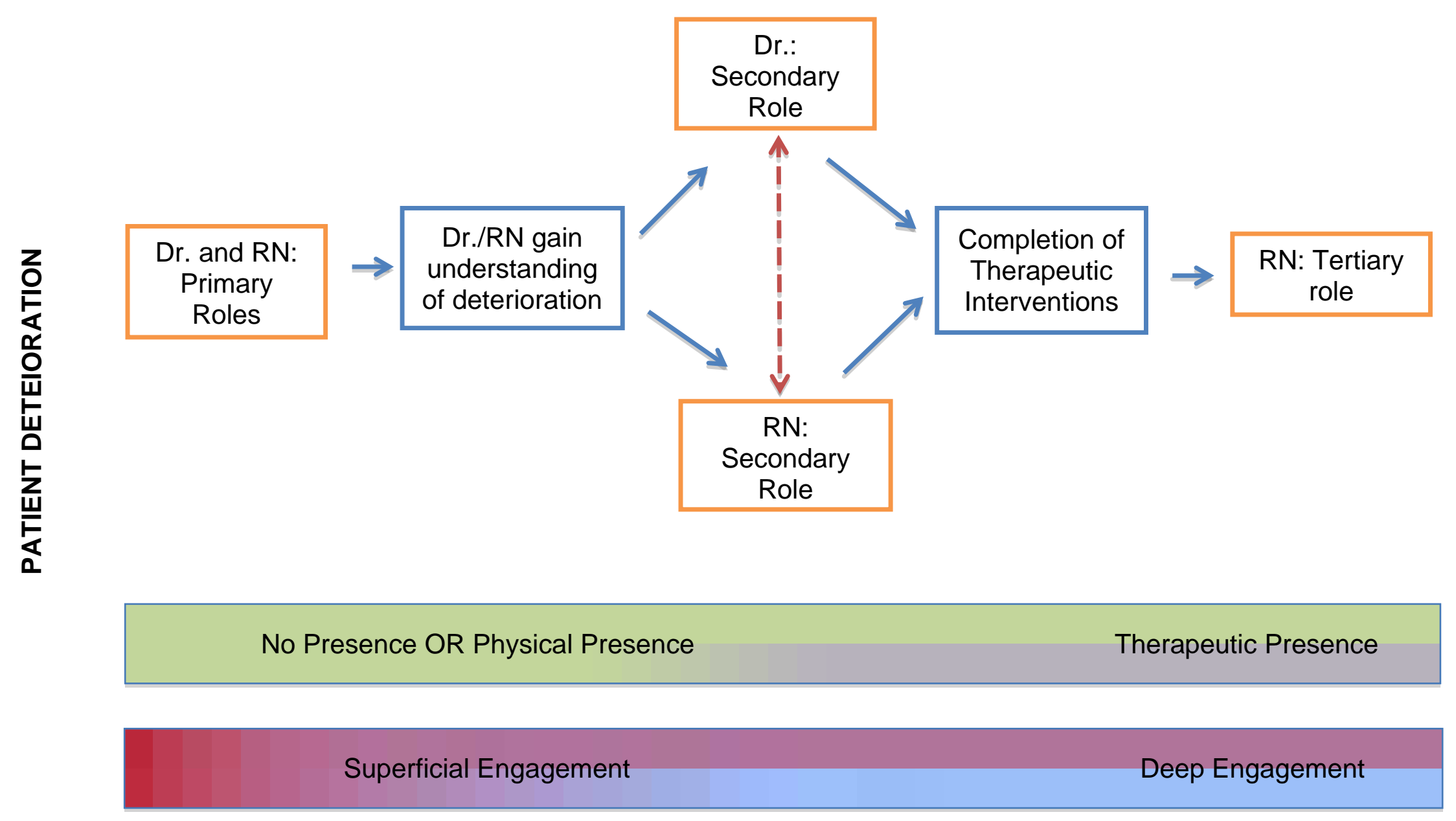

Figure 1 Model of Family Presence During Management of the Acutely Deteriorating Adult Emergency Department Patient 


\section{University Library}

\section{- M M I N E R VA A gateway to Melbourne's research publications}

Minerva Access is the Institutional Repository of The University of Melbourne

Author/s:

Youngson, MJ;Currey, J;Considine, J

Title:

Current practices related to family presence during acute deterioration in adult emergency department patients.

Date:

2017-11

Citation:

Youngson, M. J., Currey, J. \& Considine, J. (2017). Current practices related to family presence during acute deterioration in adult emergency department patients.. J Clin Nurs, 26 (21-22), pp.3624-3635. https://doi.org/10.1111/jocn.13733.

Persistent Link:

http://hdl.handle.net/11343/292685 